\title{
A Piloted Evaluation of Damage Accommodating Flight Control Using a Remotely Piloted Vehicle
}

\author{
Kevin Cunningham ${ }^{1}$, David E. Cox ${ }^{2}$, Daniel G. Murri ${ }^{3}$, and Stephen E. Riddick ${ }^{4}$ \\ NASA Langley Research Center, Hampton, VA 23681
}

\begin{abstract}
Toward the goal of reducing the fatal accident rate of large transport airplanes due to loss of control, the NASA Aviation Safety Program has conducted research into flight control technologies that can provide resilient control of airplanes under adverse flight conditions, including damage and failure. As part of the safety program's Integrated Resilient Aircraft Control Project, the NASA Airborne Subscale Transport Aircraft Research system was designed to address the challenges associated with the safe and efficient subscale flight testing of research control laws under adverse flight conditions. This paper presents the results of a series of pilot evaluations of several flight control algorithms used during an offset-to-landing task conducted at altitude. The purpose of this investigation was to assess the ability of various flight control technologies to prevent loss of control as stability and control characteristics were degraded. During the course of 8 research flights, data were recorded while one task was repeatedly executed by a single evaluation pilot. Two generic failures, which degraded stability and control characteristics, were simulated inflight for each of the 9 different flight control laws that were tested. The flight control laws included three different adaptive control methodologies, several linear multivariable designs, a linear robust design, a linear stability augmentation system, and a direct open-loop control mode. Based on pilot Cooper-Harper Ratings obtained for this test, the adaptive flight control laws provided the greatest overall benefit for the stability and control degradation scenarios that were considered. Also, all controllers tested provided a significant improvement in handling qualities over the direct open-loop control mode.
\end{abstract}

\section{Nomenclature}

$\begin{array}{ll}\text { AirSTAR } & =\text { Airborne Subscale Transport Aircraft Research } \\ \text { CONOPS } & =\text { Concept of Operations } \\ \text { CHR } & =\text { Cooper-Harper Rating } \\ \text { FCS } & =\text { Flight Control System } \\ \text { FCL } & =\text { Flight Control Law } \\ \text { GPS } & =\text { Global Positioning System } \\ \text { GTM } & =\text { Generic Transport Model } \\ \text { IMU } & =\text { Inertial Measurement Unit } \\ \text { INS } & =\text { Inertial Navigation System } \\ \text { IRAC } & =\text { Integrated Resilient Aircraft Controls } \\ \text { IVHM } & =\text { Integrated Vehicle Health Management } \\ \text { LOC } & =\text { Loss of Control } \\ \text { LPS } & =\text { Load Protection System } \\ \text { MOS } & =\text { Mobile Operation Station } \\ \text { NASA } & =\text { National Aeronautics and Space Administration } \\ \text { STS } & =\text { Stick-To-Surface } \\ \alpha & =\text { Angle of attack } \\ \beta & =\text { Angle of sideslip }\end{array}$

\footnotetext{
${ }^{1}$ Senior Research Engineer, Flight Dynamics Branch, MS 308, AIAA Member.

${ }^{2}$ Senior Research Engineer, Dynamic Systems and Control Branch, MS 308.

${ }^{3}$ NASA Technical Fellow for Flight Mechanics, NASA Engineering and Safety Center, MS 308, AIAA Senior Member.

${ }^{4}$ Research Engineer, Flight Dynamics Branch, MS 308.
} 


\section{Introduction}

Loss of control (LOC) has been one of the leading contributors to the fatal accident rate of large commercial transport airplanes ${ }^{1}$. LOC accidents are complex in that they typically have many causal factors and precursors, and they are difficult to analyze because they often involve excursions beyond the normal flight envelope. For example, LOC accidents have exhibited post-stall angles of attack and/or steep pitch and bank attitudes which exceed both autopilot design limits and pilot training requirements and therefore can make recovery to normal flight challenging.

Research has been conducted over the past decade to better understand the complex flight dynamics characteristics of large transports in abnormal flight conditions ${ }^{2-4}$. Wind-tunnel experiments have documented highly non-linear and degraded aerodynamic stability and control characteristics that occur at high angles of attack or with airframe damage. Based on these experimental data, aerodynamic models have been developed and used in piloted simulations to demonstrate flight characteristics in LOC conditions including stalls, departures, and control system failures. An important characteristic measured in these data is the degradation of stability and control characteristics that occurs when angle of attack is increased beyond the normal flight envelope.

One of the emerging solutions to the LOC problem is the use of adaptive control technologies that can recognize potentially dangerous flight conditions arising from such things as degraded stability and control characteristics. These control technologies enable the control law to change its behavior to optimize controllability, thus enabling aircraft recovery from scenarios that could otherwise result in an accident. Other technologies include onboard system monitoring and identification, controls reconfiguration, and optimal flight path control.

Flight validation of control technologies aimed at the loss-of-control problem has been recognized as a significant challenge due to the difficulties and risks associated with full-scale testing of transport airplanes in abnormal flight regimes. In response to this need, the NASA Aviation Safety Program developed flight test methods using subscale flight vehicles to effectively validate the necessary technologies without excessive risk. The Airborne Subscale Transport for Aircraft Research (AirSTAR) is a state-of-the-art facility specifically designed for the purpose of investigating and validating high-payoff technologies aimed at the LOC problem ${ }^{5,6}$.

The AirSTAR infrastructure was designed to support the aeronautics research objectives of the Integrated Resilient Aircraft Control (IRAC) and Integrated Vehicle Health Management (IVHM) projects. These projects emphasize flight research under adverse conditions such as upsets (unusual attitudes and post-stall flight), control surface faults, damage (e.g. missing wing segments), and sensor failures. AirSTAR vehicles are designed for testing in regimes beyond the normal flight envelope and/or with degraded stability and control characteristics.

This paper discusses the use of piloted evaluations to assess the ability of both adaptive and conventional flight control laws to provide resilient control of a $5.5 \%$ dynamically scaled remotely piloted airplane when the stability and control characteristics are degraded. In this investigation, the pilot ratings are used as a comparative measure as opposed to a predicting full-scale airplane handling qualities. It should be noted that all ratings are from a single pilot and that, in general, repeated measurements were not made. Because of the sparse data set, this study should be considered an initial screening study to guide future research.

\section{System Overview}

\section{A. Concept of Operations}

The AirSTAR infrastructure is comprised of a research flight vehicle, the mobile operation station (MOS), and the safety pilot as illustrated in Fig. 1 The MOS is comprised of a flight test control room and the research pilot station as well as systems and engineering stations. As illustrated in Fig. 1, takeoff and landing is accomplished by a safety pilot using direct visual contact and conventional radio control equipment. After takeoff, control is transferred to the research pilot. The research pilot executes all flight test maneuvers from inside the MOS, using a synthetic vision display drawn from telemetry data and a local terrain database. When using this concept of operation, the safety pilot is responsible for both flight termination function and reversionary flight control capability. Thus, all maneuvers must be performed within visual range of the safety pilot. This concept of operation provides a flexible environment to conduct flight research and rapidly evaluate research flight control laws with minimal risk to persons and property. 


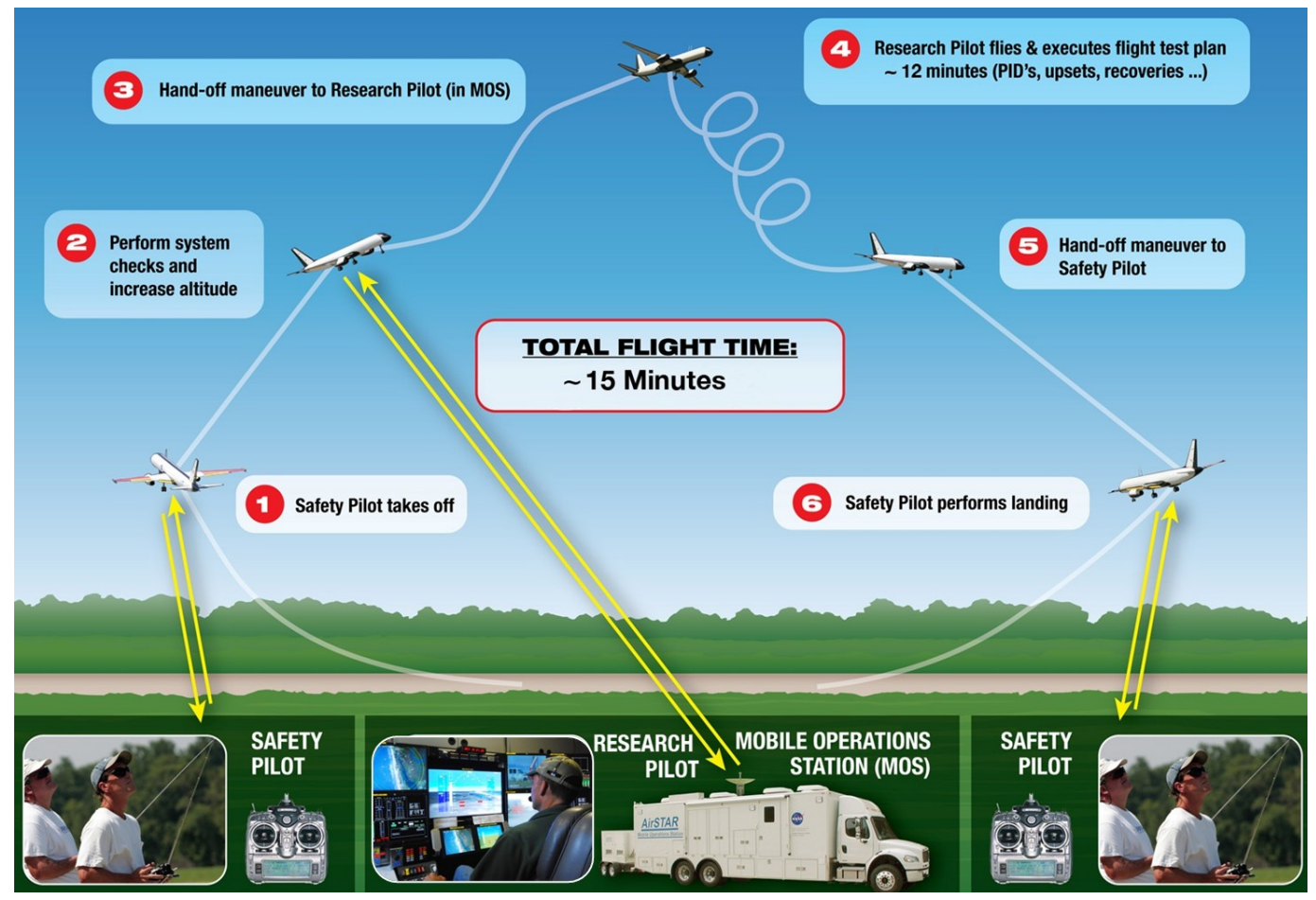

Figure 1. Illustration of AirSTAR concept of operations.

\section{B. Airplane Description}

This study was conducted using a remotely piloted unmanned model airplane. The airplane is not only $5.5 \%$ geometrically scaled, but also dynamically scaled. Dynamic scaling techniques ${ }^{7}$ were used so that the flight dynamics of the model would be appropriately scaled and representative of a generic transport airplane with twin under wing mounted engines and a convention tail. This AirSTAR vehicle is referred to as the Generic Transport Model (GTM), tail number T2. The mass properties of the airplane represent a transport airplane with a standard load configuration at mid weight and mid center of gravity. The subscale airplane has a wingspan of 6.8 feet and length of 8.5 feet. The airplane has a takeoff weight of 58 pounds and a typical landing weight of 48 pounds. The airplane is powered by two jet engines, which each produce 16 pounds static thrust.

The airplane has a complete set of flight test instrumentation. The airplane has a micro-Inertial Navigation System (INS) which outputs 3-axis linear accelerometer measurements, angular rate measurements, Euler angles, and GPS velocity and position. An analog micro-Inertial Measurement Unit (IMU) which provides redundant and low latency 3-axis linear accelerometer and angular rate measurements is also installed. This low latency microIMU is the primary rate and acceleration feedback source to the flight control laws. Air data instrumentation is mounted on wingtip booms (visible in Fig. 2) that measure angle of attack, angle of sideslip, dynamic pressure, and static pressure. A thermocouple is flush mounted on the fuselage to measure outside air temperature. The primary flight control surfaces: ailerons, elevators, and rudders are equipped with control surface position transducers. Furthermore, the rudder is divided into upper and lower surface segments and the left and right elevators are divided into four segments. The purpose of dividing the flight control surfaces is to have control redundancy. Modified commands can be sent to the redundant surfaces to degrade the airplane stability and control characteristics. Secondary surfaces on the airplane are inboard and outboard spoiler panels which are used for roll control (in some of the research flight control laws), speed brake function, and, on demand, flying qualities degradation.

To meet dynamically scaled weight and inertia targets, the system uses a ground based flight control computer. All control laws are run on the ground-based computer, with the resultant commands being uplinked to a flight control unit located onboard the airplane. This unit handles sensor data collection, telemetry serial stream parsing and creation, command switching, and actuator command generation. The telemetry link is comprised of an L-band uplink and S-band downlink. The update rate is $200 \mathrm{~Hz}$. 


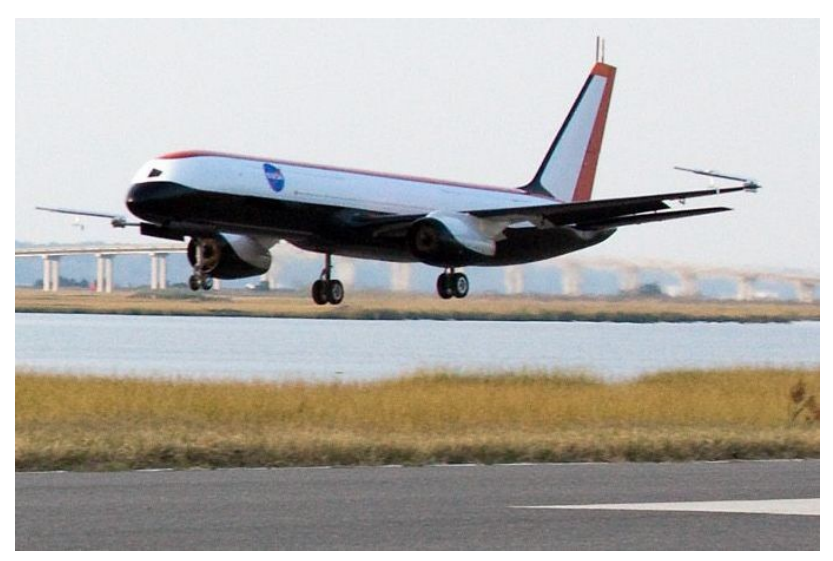

Figure 2. Generic Transport Model tail number T2.

\section{Flight Control System Description}

The AirSTAR Flight Control System ${ }^{6}$ (FCS) uses a reversionary build-up approach to mitigate the risks associated with flight testing complex research control laws. Complexity is added in distinct stages that can be quickly transitioned using a two-switch "arm" and "engage" process. The FCS is separated into three flight control law (FCL) modes, shown in Fig. 3. These three control law modes are mutually exclusive; only one can be active at a time. Mode 1 is a direct, stick-to-surface (STS) control law composed of stick shaping only; no sensor feedback is used. This mode has a simple design by choice and has proven to provide adequate flying qualities for a wide range of test techniques. Mode 2 is the baseline conventional (non-adaptive) closed-loop controller and was not evaluated during this investigation. Mode 3 is reserved for the research control laws, and can contain numerous FCLs. Thirteen research FCLs are currently implemented, and eight of those research FCLs and one direct stick-to-surface FCL were evaluated during this study.

The FCS also contains auxiliary modules that can be used in conjunction with Modes 1, 2, or 3: a Wavetrain module, a Model Tracking \& Failures module, and a Load Protection System (LPS) module. The Wavetrain module provides the capability to inject arbitrary automated control surface perturbation commands. The perturbation commands are added to the active commands (Fig. 3), upstream of the LPS and Model Tracking \& Failures modules. The primary purpose of the perturbations is to perform system identification analysis. The Model Tracking $\&$ Failures module, positioned downstream of the Wavetrain input module in Fig. 3 provides the capability to simulate failures during flight by modifying any of the control surface commands. A large number of user-defined failure profiles can be implemented, which are then selected and engaged by the flight test engineer during flight research. The purpose of the LPS is to prevent the FCS from commanding control deflections that would result in excessive structural load on the test aircraft. The Transfer Logic module provides mode arming, engagement, and safety related mode engagement inhibits. The input selection module ensures that when mode changes occur, the surface commands remain transient free.

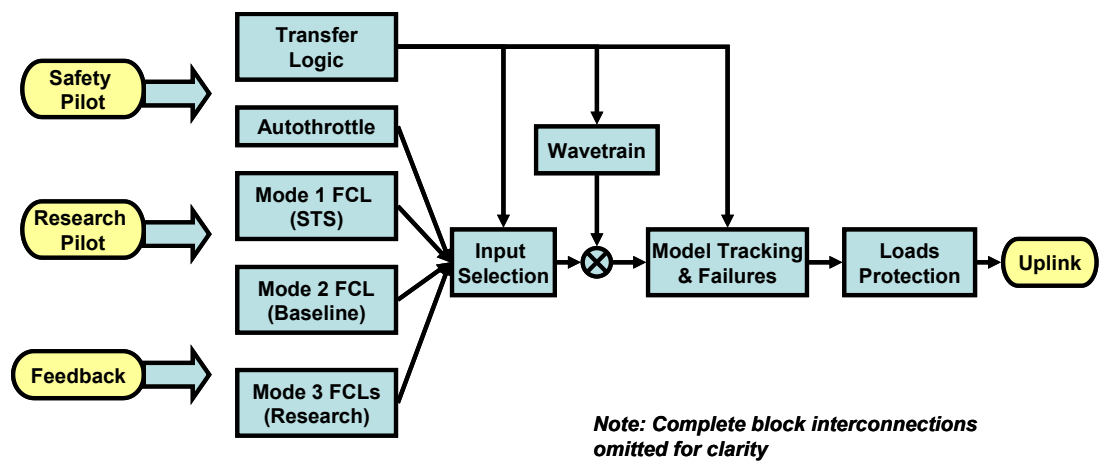

Figure 3. AirSTAR flight control system high level block diagram. 


\section{Cockpit Description}

The AirSTAR MOS serves as both a flight test control room and remotely piloted vehicle cockpit. Figure 4 shows a photo of the cockpit with the pilot in the foreground. The test conductor is seated to the pilot's right, while the FTE is seated on the pilot's left (not shown in photo). The flight test engineer manages systems and research functions so that the pilot can keep his hands on the throttles and control stick at all times. The airplane is flown with a side-stick controller. The stick forces are provided by springs and are proportional to displacement. Maximum deflection of the control stick is 28 degrees from center, which equates to an approximate 3 inch displacement at the location of the pilots thumb and index finger. A summary of the stick force characteristics is presented in Table1.

Table 1. Side-Stick Controller Force Characteristics

\begin{tabular}{|l|c|c|}
\hline $\begin{array}{c}\text { Direction of } \\
\text { Movement }\end{array}$ & $\begin{array}{c}\text { Breakout } \\
\text { Force } \\
(\mathrm{lbs})\end{array}$ & $\begin{array}{c}\text { Maximum } \\
\text { Force } \\
(\mathrm{lbs})\end{array}$ \\
\hline Left & 0.4 & 2.9 \\
\hline Right & 0.4 & 3.0 \\
\hline Forward & 1.0 & 3.4 \\
\hline Aft & 1.3 & 3.7 \\
\hline
\end{tabular}

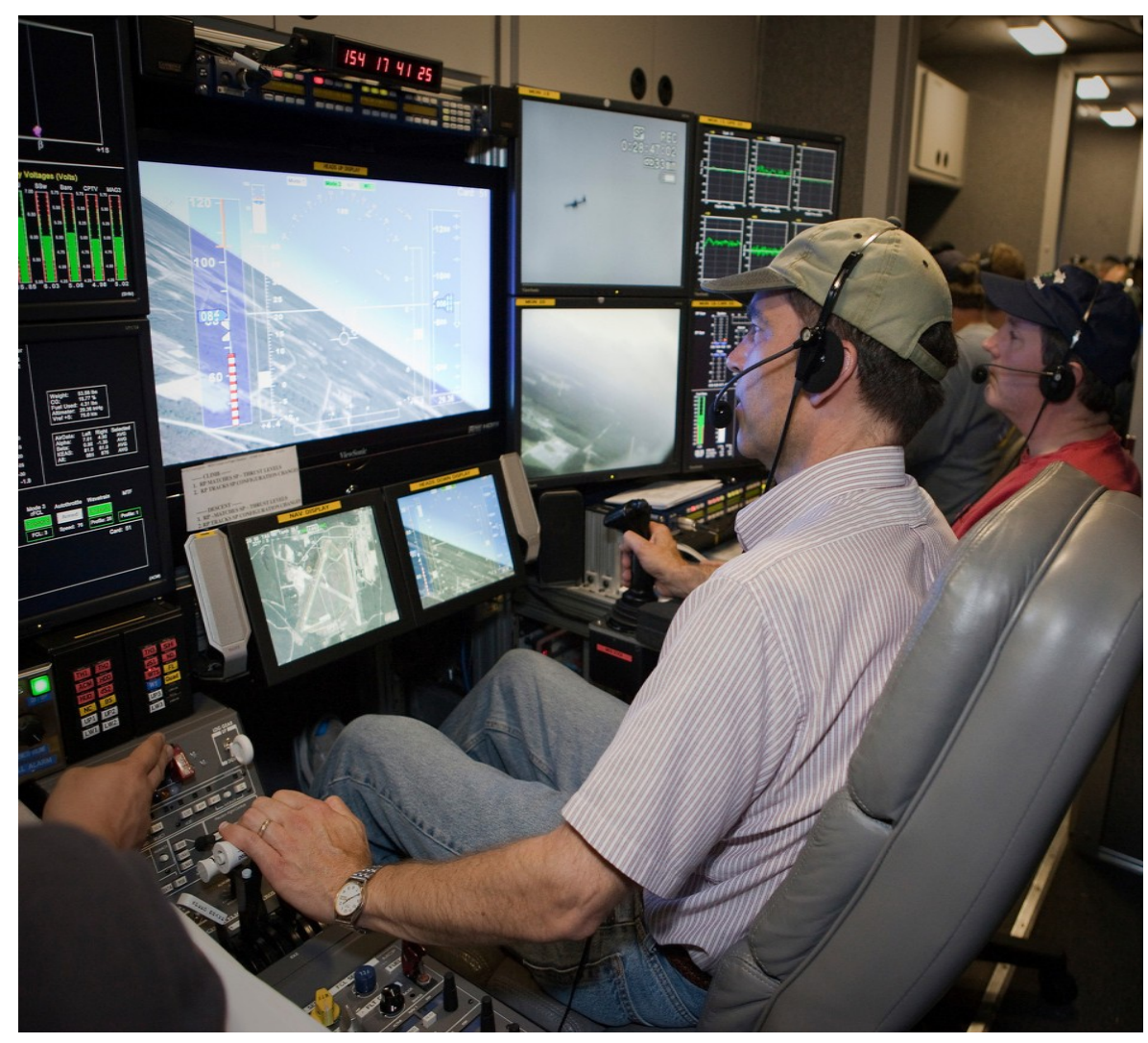

Figure 4. AirSTAR research cockpit. 


\section{Failure Simulation and Stability Degradation Descriptions}

Designing controllers to accommodate aircraft failures is a particularly challenging problem due to the lack of a priori knowledge of the resulting aircraft stability and control characteristics. In simulation a wide range of conditions may be evaluated via Monte-Carlo, however for flight test evaluation the test matrix is very limited. It is important, therefore, to choose a test scenario that is general in nature and representative of a class of potential failure conditions. In this study three failure cases were considered for evaluation, an asymmetric elevator failure, latency injection in the feedback loop, and degraded aircraft stability.

The asymmetric elevator failure was implemented as a "stuck surface", with one side of the segmented elevator being frozen at its trim condition. This caused a 50\% decrease in pitch authority and introduces a pitch/roll coupling in the vehicle's response to longitudinal stick inputs. In the open-loop system this failure made it more difficult for the pilot to perform precision turns. The closed-loop controllers, however, could easily accommodate this type of failure to the point where the pilot could not detect its occurrence. Since the asymmetric elevator failure was not useful as a performance discriminator it was dropped as one of the common test conditions and will not be detailed here further.

An increase in signal latency is not easily tied to a particular physical system failure; however, as a generic measure of controller robustness it is still very useful. It is closely related to the phase margin in linear controller analysis and controllers with a high sensitivity to time delay tend to be sensitive to model fidelity or instrumentation errors. For in-flight evaluation each controller was subjected to pure time delay in the actuation path. Once initiated, this delay was continually increased (in $5 \mathrm{msec}$ increments and held for 5 seconds before the next increment was applied) as the controller followed reference stick-input commands until the response was deemed to be a sustained oscillatory divergence. Controllers which tolerated high time delays are more robust, but may not provide adequate performance under failure conditions.

The most comprehensive controller test was multi-axis degradation of stability and control characteristics. These scenarios posed a significant challenge for the flight control systems to retain baseline handling qualities. The goal of the control laws was to enable pilot ratings which were consistent with baseline ratings as the stability and control characteristics were incrementally degraded. Three failure scenarios were used in this investigation. Scenario "A" represents the baseline airframe with all control surface commands being nominal. Scenarios "B" and "C" used redundant flight control surfaces, scheduled with angle of attack or roll rate to degrade the longitudinal static stability and the roll damping simultaneously (Fig. 5). Scenario B provides approximately neutral longitudinal static stability and neutral roll damping. Scenario " $\mathrm{C}$ " provides unstable longitudinal static stability and unstable roll damping. For scenario " $\mathrm{C}$ " the apparent (to the $\mathrm{FCL}$ ) $\mathrm{Cm}_{\alpha}$ and $\mathrm{Cl}_{\mathrm{p}}$ are positive in sign (unstable) and approximately $25 \%$ of the baseline magnitude. This approach to stability degradation also has the effect (while engaged) of degrading the nominal elevator effectiveness by $50 \%$ and eliminating the option of using roll spoiler. Activation and deactivation of these degradations were controlled by the flight test engineer upon the pilot's verbal command.

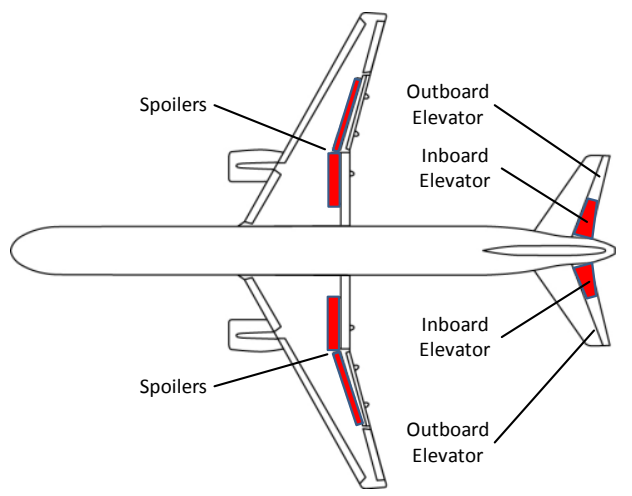

Figure 5. GTM with control surfaces used for stability and control degradation highlighted. 


\section{Evaluation Task Description}

One of the objectives of the IRAC project is to advance the state of the art of adaptive flight control technologies as a design option to provide stability and maneuverability margins for safe landing in the presence of adverse conditions, including damage and failure. Two tasks were used in this inflight study. The first, which involved flying a figure 8 pattern, was to determine controller sensitivity to time delay. The second task was more comprehensive and did not include artificial time delay. That (offset-to-landing) task was developed to provide a high gain, high precision and operationally relevant maneuver to evaluate the performance of the various control laws in providing adequate handling qualities and maneuver performance in the presence of simulated failures or damage to the airplane. Better controllability, of course, leads to higher probability of safe and survivable landings. Data used to assess the effectiveness of the control laws included time-history parameter recordings, pilot comments, and a pilotassigned Cooper Harper Rating (CHR). Figure 6 shows the CHR scale and logic for each rating.

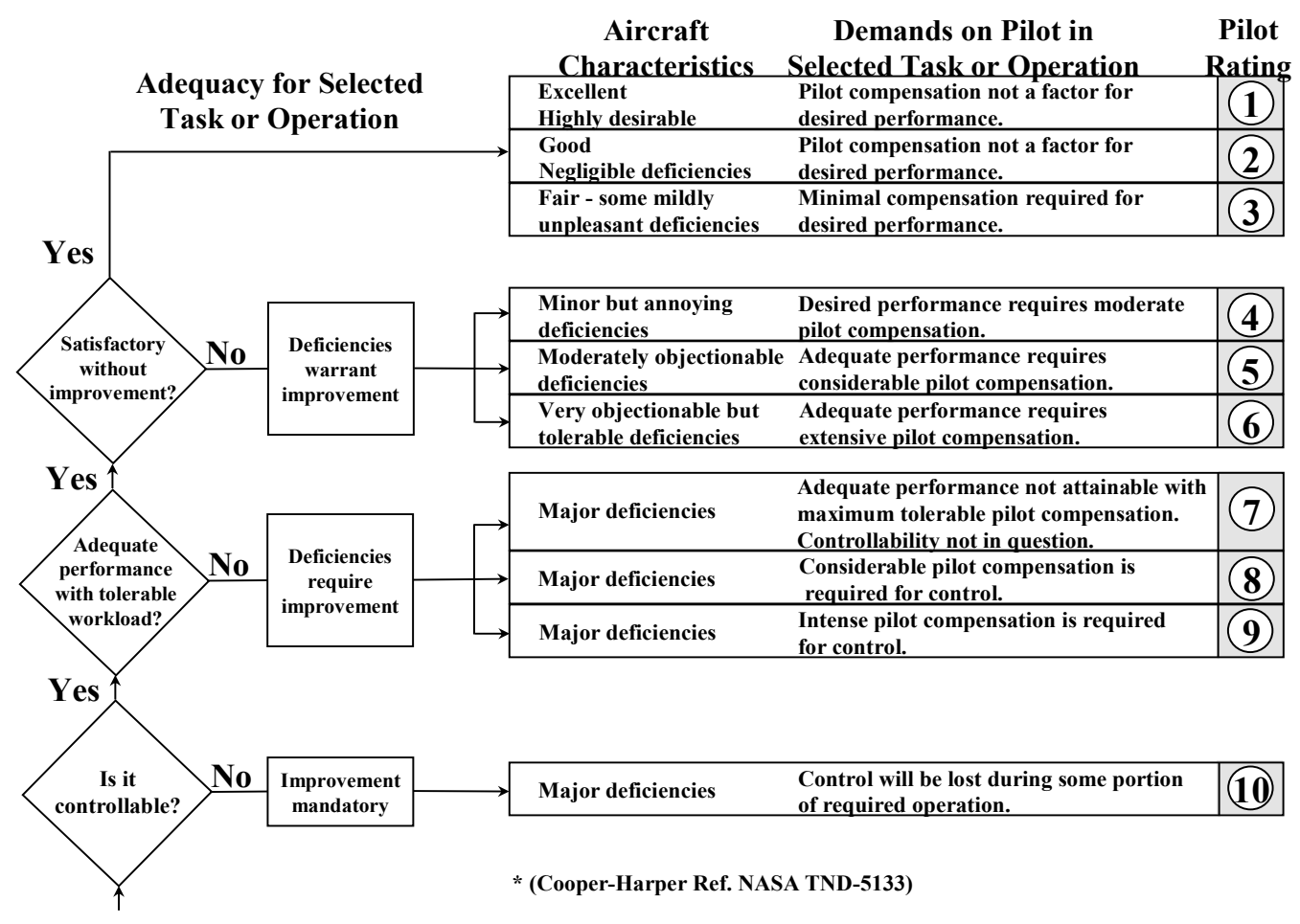

Figure 6. Cooper-Harper rating scale.

To assess controller sensitivity to time delay, the defined task was to continuously fly a figure 8 profile at constant airspeed and altitude. The pilot was not required to fly to precise tolerances. While the pilot was performing this task, a system failure simulation was engaged. That failure simulation injected artificial time delay in all the control surface actuator command paths. Once started, the time delay was continually increased in discrete 5 msec steps. On straight legs, to evaluate command tracking capability, the pilot alternately exercised the pitch and roll axes with long duration, small amplitude doublets. The task was considered complete when a sustained divergent oscillatory response was noted or the incremental time delay reached the maximum $(200 \mathrm{msec})$.

The offset-to-landing task was started 100 feet left, 100 feet above and 1,800 feet downrange of a target reference position. This maneuver normally took about 15 seconds and required the pilot to perform an "s-turn" to align with the runway. To manage the risk of damage to the model airplane, the offset-to-landing task profile was performed at a normal operational altitude (1,000 feet above ground level). The task was performed by momentarily biasing the pilot's synthetic Head Up Display (HUD) to give the compelling appearance of being on a short, offset final approach. The pilot's task was to penetrate a touchdown zone target box at a 3 degree descent angle with the wings level. A landing flare was not performed. The task was considered finished when the eye point descended below the altitude of the target box. At task completion the pilot assessed performance by referencing the bank angle pointer and flight path marker to green markers on the synthetic display which represent target, desired, and adequate task criteria (Fig. 7). Table 2 details the target, desired, and adequate task performance criteria to be applied when the target box altitude was penetrated. 
Table 2. Offset Landing Task Criteria

\begin{tabular}{|l|c|c|c|}
\hline & Target & Desired & Adequate \\
\hline Bank Angle, deg & 0 & \pm 10 & \pm 20 \\
\hline Flight Path Angle, deg & -3 & \pm 1 & \pm 3 \\
\hline Lateral Offset, feet & 0 & \pm 12 & \pm 24 \\
\hline Longitudinal Offset, feet & 0 & \pm 164 & \pm 363 \\
\hline
\end{tabular}

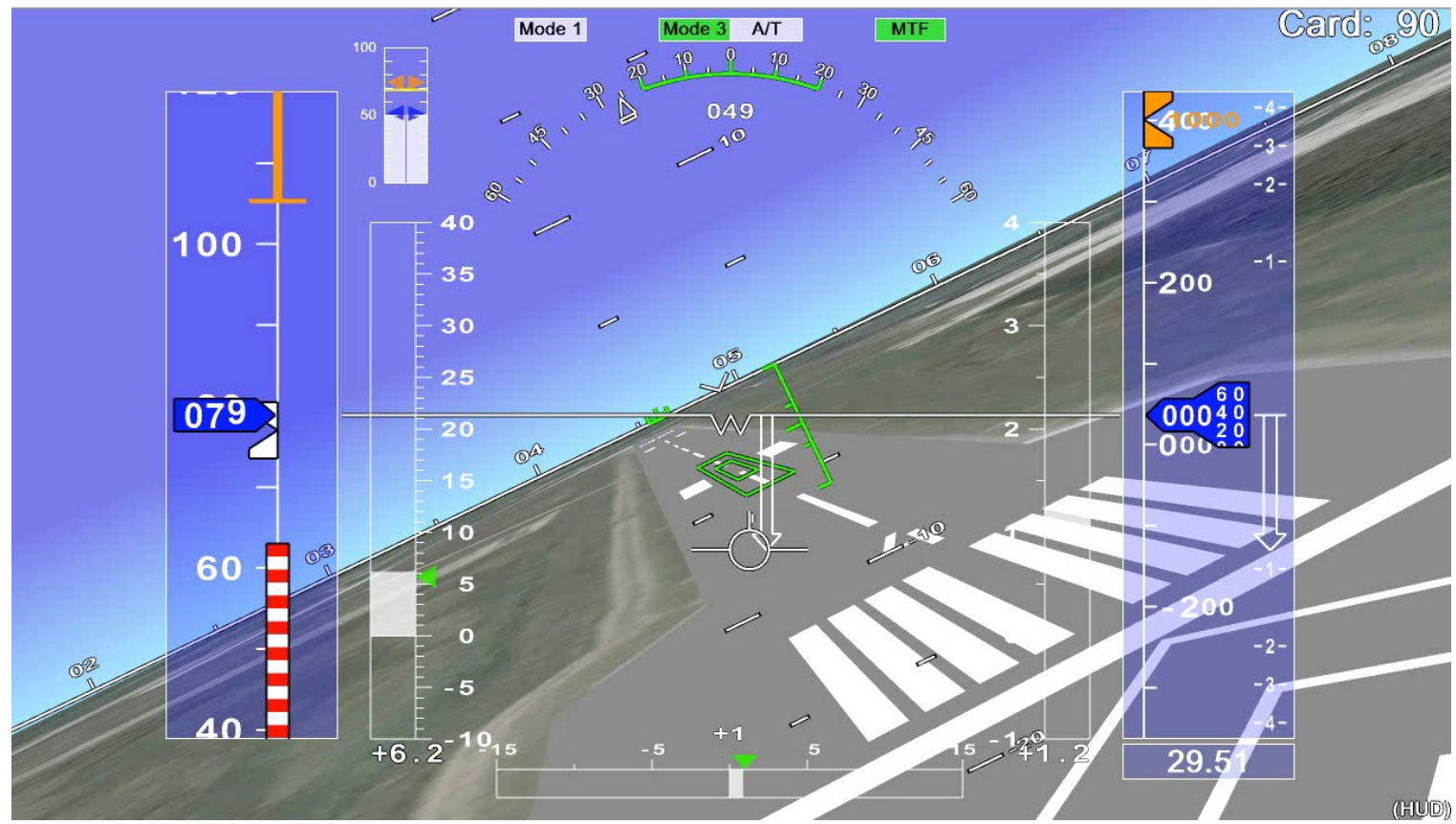

Figure 7. HUD showing (in green) target markers for: flight path, touchdown zone, and bank angle.

In general, 4 offset-to-landing task profiles were flown for each of the control laws that were evaluated. The first profile flown was for practice and was not rated or commented on by the pilot. The following three were the sequence of scenarios A, B, and then C. Immediately after each offset-to-landing task, the test conductor questioned the pilot, who provided concise commentary about: controllability, task performance, workload tolerability, and level of pilot compensation. CHRs where not obtained at that time. This was due to limited endurance of the model and the compressed size of the test range which created high pilot workload. CHRs were obtained within 10 minutes of the evaluation tasks being completed. This occurred as the pilot viewed a fully synchronized playback of all displays, audio (including in-situ comments about workload, compensation, etc.), and video of the tasks just flown. At that time, the pilot expanded on his inflight comments, then assigned a CHR while referencing the rating scale flow chart. Non integer CHRs were not allowed. While in flight, the pilot was allowed to request a scenario repeat if he felt he made a technical error effecting task execution. All CHRs are reported. None are averaged.

Note that in this study, the CHRs are being used as relative indicators of handling qualities. CHRs obtained in this study would not necessarily equate to those obtained in the operation of the full scale airplane. This is for several reasons. Although the flight dynamic response of the model airplane is scaled (4 times faster than the full scale airplane), the human pilot is not dynamically scaled. Also, the pilot in this study is piloting remotely and using a cockpit not representative of a full scale transport airplane cockpit. 


\section{Research Flight Control Law Descriptions}

Research control algorithms for the study were provided by a number of academic and industry participants, each working in the $3^{\text {rd }}$ year of NASA Research Announcement awarded grants/contracts from NASA's Aviation Safety Program, Integrated Resilient Aircraft Control Project. The designs were based on a common non-linear simulation model. This model included an expanded aerodynamic database for the vehicle, as well as detailed models for engines, control surface actuators, sensors, and time delay effects introduced through the avionics. It also contained a set of failure cases for structural faults and control surface failures. These included control power and mass/inertia changes, as well as aerodynamic increments based on wind tunnel testing of the failed configuration. Many of the controllers were designed against these failures, however in flight a generalized stability degradation fault was implemented, as discussed earlier. All the intended testing was to be performed at a single flight condition, trimmed flight at $1.3 \mathrm{~V}_{\text {stall }}+5 \mathrm{knots}$, where $\mathrm{V}_{\text {stall }}$ is the $1 \mathrm{~g}$ stall speed. Therefore the controllers were generally designed against a single reference model, without gain scheduling or other explicit consideration of aerodynamic nonlinearities.

Although the simulation model was common to all participants, the designs were not otherwise constrained, and several different approaches were considered. The control algorithms tested included a direct stick-to-surface system, a decoupled stability augmentation system, 4 linear multivariable feedback controllers, 2 adaptive augmentation controllers, and 1 all-adaptive control law. Each controller highlighted different aspects of the desired robustness to faults, as well as different targets for nominal response characteristics, and different pilot reference commands. Table 3 summarizes these general design characteristics. A full description of the design methods and their implementation is provided in the references ${ }^{8-12}$ and in analysis papers from the same authors being prepared concurrently with this paper.

Table 3. Controller Suite, Design Methods and Reference Command Axes

\begin{tabular}{|c|l|c|c|c|l|}
\hline ID & \multicolumn{1}{|c|}{ Design Method } & $\begin{array}{c}\text { Pitch } \\
\text { Axis }\end{array}$ & $\begin{array}{c}\text { Roll } \\
\text { Axis }\end{array}$ & $\begin{array}{c}\text { Yaw } \\
\text { Axis }\end{array}$ & \multicolumn{1}{|c|}{ Reference \# } \\
\hline 1.0 & Direct Pilot Control & Elevator & Aileron & Rudder & \multicolumn{1}{|c|}{ - } \\
\hline 3.3 & $\begin{array}{l}\text { Deriv. Free MARC } \\
\text { Adaptive Augmentation }\end{array}$ & Pitch Rate & Roll Rate & Rudder & Yucelen, et.al. (Ref. 8) \\
\hline 3.4 & $\begin{array}{l}\text { LQR } \\
\text { Linear Optimal }\end{array}$ & Pitch Rate & Roll Rate & Rudder & Yucelen, et.al. (Ref. 8) \\
\hline 3.5 & $\begin{array}{l}\text { LQR } \\
\text { Integrated Propulsion }\end{array}$ & $\alpha$ & Roll Rate & $\beta$ & Crespo, et.al. (Ref. 9) \\
\hline 3.7 & $\begin{array}{l}\text { L1 Adaptive } \\
\text { All Adapt }\end{array}$ & $\alpha$ & Roll Rate & $\beta$ & Gregory, et.al. (Ref. 10) \\
\hline 3.8 & $\begin{array}{l}\text { Stability Augmentation } \\
\text { Robust Linear }\end{array}$ & $\begin{array}{c}\text { Elevator, } \\
\text { SAS }\end{array}$ & $\begin{array}{c}\text { Aileron, } \\
\text { SAS }\end{array}$ & $\beta$ & Dorobantu, et.al. (Ref. 11) \\
\hline 3.9 & $\begin{array}{l}\text { H-Infinity } \\
\text { Robust Linear }\end{array}$ & $\alpha$ & $\begin{array}{c}\text { Aileron, } \\
\text { SAS }\end{array}$ & $\beta$ & Dorobantu, et.al. (Ref. 11) \\
\hline 3.10 & $\begin{array}{l}\text { Composite MRAC } \\
\text { Adaptive Augmentation }\end{array}$ & $\alpha$ & Roll Rate & $\beta$ & Gadient, et.al. (Ref. 12) \\
\hline 3.11 & $\begin{array}{l}\text { LQR-PI } \\
\text { Linear Optimal }\end{array}$ & $\alpha$ & Roll Rate & $\beta$ & Gadient, et.al. (Ref. 12) \\
\hline
\end{tabular}




\section{Results}

Phase margin, or in a more general setting time-delay margin, is an important design consideration for feedback controllers. Generally, high-gain and high-performance controllers will exhibit a sensitivity to time delay in the control path, and this indicates a lack of robustness to instrumentation lags and to broader forms of model uncertainty. The process of tuning a control algorithm varies widely with design method, but it almost always involves exploring the fundamental trade between performance and robustness.

In the AirSTAR flight tests, time delay served as a proxy for robustness. Each controller was tested against a simulated latency failure condition. During simulated failure, the pilot performed low-gain horizontal figure-8 maneuvers and both pitch and roll axis doublets. The injected time-delay caused the response characteristics to degrade and become oscillatory. When the oscillatory response was judged to be sustained and growing, the latency fault was terminated. This was not a precise measure of the onset of instability, but did represent the time delay at which the vehicle was rapidly becoming uncontrollable. The latency test results are detailed in Table 4. The maximum latency tested was limited to $200 \mathrm{msec}$.

All of the offset-to-landing task evaluations were performed over the course of the final 3 days of a 14 day flight test campaign conducted between August 29 and September 11, 2010. All sorties were flown in compliance with an FAA certificate of authorization at Allen C. Perkinson / Blackstone Army Airfield (KBKT) located in Blackstone, Virginia. Earlier in the campaign, the research pilot gained FCL familiarity when he flew the suite of flight control laws while performing other evaluation tasks and maneuvers. To minimize the effect of learning during the offsetto-landing task, day-of-flight simulation sessions were performed. During these simulation sessions, the research pilot was able to rapidly perform a series approximately 30 offset-to-landing tasks. Failure scenarios were not engaged during the day-of-flight simulation sessions. To minimize the effect of winds aloft the simulator was loaded with the current "1,000 ft" winds aloft measured by the Nation Weather Service Doppler weather radar (WSR-88D) located in Wakefield, Virginia. To minimize the effects of low altitude turbulence due to diurnal heating, research flights began at 30 minutes after sunrise. Typically, flight operations were ceased about 4 hours after sunrise (when turbulence adversely affected data quality).

Table 4: Time Delay Resulting in Unstable Dynamics During Inflight Evaluations

\begin{tabular}{|c|l|c|}
\hline ID & \multicolumn{1}{|c|}{ DESIGN METHOD } & Injected Time Delay \\
\hline 3.8 & $\begin{array}{l}\text { Stability Augmentation } \\
\text { Robust Linear }\end{array}$ & $>200 \mathrm{msec}$ \\
\hline 3.4 & $\begin{array}{l}\text { LQR } \\
\text { Linear Optimal }\end{array}$ & $185 \mathrm{msec}$ \\
\hline 3.9 & $\begin{array}{l}\text { H-Infinity } \\
\text { Robust Linear }\end{array}$ & $110 \mathrm{msec}$ \\
\hline 3.5 & $\begin{array}{l}\text { LQR } \\
\text { Integrated Propulsion }\end{array}$ & $105 \mathrm{msec}$ \\
\hline 3.7 & $\begin{array}{l}\text { L1 } \\
\text { All Adaptive }\end{array}$ & $105 \mathrm{msec}$ \\
\hline 3.3 & $\begin{array}{l}\text { Deriv. Free MARC } \\
\text { Adaptive Augmentation }\end{array}$ & $70 \mathrm{msec}$ \\
\hline 3.11 & $\begin{array}{l}\text { LQR-PI } \\
\text { Linear Optimal }\end{array}$ & $\begin{array}{l}\text { Composite MRAC } \\
\text { Adaptive Augmentation }\end{array}$ \\
\hline 3.10 & \\
\hline
\end{tabular}


Table 5 provides the concise summary comments and CHRs that the AirSTAR research pilot provided for the offset-to-landing task evaluations. These data are tabulated by flight number and also contain the pilot's qualitative assessment of turbulence during the flight. For each of these flights, one inflight practice offset-to-landing task was performed to further mitigate the effects of learning. Additional practice was not conducted due to fuel limitations. The pilot did not provide comments or ratings associated with the practice task. After execution of the practice task, scenarios A, B, and C were flown in a buildup sequence. The elapsed time between the start of each successive task was approximately 90 seconds. Because the entire failure buildup was completed in less than 5 minutes, the effects of turbulence and crosswind are considered constant during the time that each individual control law was being evaluated. Table 6 documents notes and expanded pilot comments from evaluation flight debriefings. Time history and trajectory plots for all FCLs and scenarios can be found in the figures 8-16. These plots are useful for understanding pilot comments and ratings.

On two occasions the research pilot requested a repeat because he felt his performance compensating for environmental effects was abnormal and compromised the result. The first occasion was on flight 39 , during the very first task rating attempt; the pilot stated that he made an error in his crosswind compensation. The second occasion was on flight 44, during evaluation of the direct (no feedback) control mode with scenario A; the pilot felt that turbulence had significantly degraded his performance. The pilot's qualitative assessment of turbulence for that flight was "moderate or greater" and was substantiated by spectral analysis of in-flight vertical gust estimates. It should be noted that the pilot did not bias his evaluations to compensate for environmental or other factors. Pilot comments regarding effect of crosswind, turbulence or other factors are captured in Table 6 . The pilot did state that he felt the effects of crosswind and turbulence caused some of his CHR ratings to be biased 1 CHR higher than they otherwise would have been.

A review of Table 6 and inspection of time history data plots in figures 8-16 shows that the most challenging aspect of the failures was controllability in the roll axis. This is attributed to the aspect of the failure scenarios that reduced roll damping. On several occasions, the pilot commented on persistent limit cycle oscillations during scenario B. Scenario C was most often abandoned due loss of control in the roll axis. The exception to this was FCL 3.5 which integrated propulsion control with the pitch axis control. For scenario A, the pilot comments included statements that the airplane was difficult to trim and that he was "working pretty hard". For this controller, scenario $\mathrm{C}$ was abandoned late in the run due to activation of the FCS loads protection system when normal load factor exceeded task limits.

Table 7 shows further simplification of the evaluation data in Table 5. The sorting (top to bottom) in this table represents the degree to which an individual controller retained its baseline handling qualities for scenario $\mathrm{B}$ (inflight simulation of neutral stability: $\mathrm{Cl}_{\mathrm{p}} \sim 0$ and $\mathrm{Cm}_{\alpha} \sim 0$, elevator effect degraded $50 \%$, and spoilers inoperative). Care should be taken not to directly compare design methodologies, especially for the baseline scenario. This is because of the variations in individual control law design detail, variation in test day conditions, use of a single evaluation pilot, and variation in control law design philosophy relating to controller performance vs. stability tradeoffs. Table 7 makes use of the following definition: Level $1=1 \leq \mathrm{CHR} \leq 3$, Level $2=4 \leq \mathrm{CHR} \leq 6$, Level $3=7 \leq \mathrm{CHR} \leq 9$. The table is color coded green, yellow, red respectively. Black color coding indicates lossof-control or task abandoned. These data show that in this study, all the adaptive controllers that were tested preserved level 2 handling qualities for scenario "B" and the ability to control the airplane for scenario " $\mathrm{C}$ " was also preserved. Particularly noteworthy is that for FCL 3.10, the pilot rating did not degrade when scenario "B" was tested. The piloted noted small oscillations (Fig. 11) for that scenario, but it did not significantly affect his workload, compensation, or task performance. FCL 3.7 degraded gracefully (down 2 CHR per fault) and completed scenario "C" with CHR 7 (Table 7 and Fig. 10). With the exceptions of FCLs 3.10 and 3.7, scenario "C" ratings indicate loss of control, or questionable controllability. Despite the handling qualities cliff for scenario "C", FCL 3.9 preserved handling qualities for scenario "B" to a degree that was comparable to some of the adaptive FCLs (Table 7 and Fig. 10). The most abrupt drop in handling qualities rating was seen for FCL 1.0, direct control (no feedback control). With the direct control mode, loss of control occurred immediately after the scenario "B" failure was engaged (Fig. 13). Use of any of the other controllers tested with this scenario provided significantly higher controllability margins than the direct control mode. 
Table 5. Summary of Comments and Cooper-Harper Ratings From Evaluation Flights

\begin{tabular}{|c|c|c|c|c|c|c|c|c|}
\hline $\begin{array}{c}\text { Flight } \\
\#\end{array}$ & Turbulence & FCL & Scenario & Controllable & Performance & $\begin{array}{l}\text { Workload } \\
\text { Tolerable }\end{array}$ & $\begin{array}{c}\text { Pilot } \\
\text { Compensation }\end{array}$ & CHR \\
\hline \multirow{3}{*}{39} & \multirow[t]{3}{*}{ Smooth } & 3.9 & $\begin{array}{l}\text { A } \\
\text { A }\end{array}$ & $\begin{array}{l}\text { Yes } \\
\text { Yes }\end{array}$ & $\begin{array}{l}\text { Adequate } \\
\text { Desired }\end{array}$ & $\begin{array}{l}\text { Yes } \\
\text { Yes }\end{array}$ & $\begin{array}{l}\text { Moderate } \\
\text { Minimal }\end{array}$ & $\overline{3}$ \\
\hline & & 3.9 & B & Yes & Desired & Yes & $\begin{array}{l}\text { Considerable } \\
\text { for Control }\end{array}$ & 5 \\
\hline & & 3.9 & $\mathrm{C}$ & No & - & - & - & 10 \\
\hline \multirow{3}{*}{40} & \multirow{3}{*}{ Smooth } & 3.8 & A & Yes & Desired & Yes & Minimal & 3 \\
\hline & & 3.8 & B & In Question & $\begin{array}{c}\text { Not } \\
\text { Adequate }\end{array}$ & & $\begin{array}{l}\text { Considerable } \\
\text { for Control }\end{array}$ & 8 \\
\hline & & 3.8 & $\mathrm{C}$ & No & - & - & - & 10 \\
\hline \multirow{3}{*}{41} & \multirow{3}{*}{ Light } & 3.7 & A & Yes & Desired & Yes & Minimal & 3 \\
\hline & & 3.7 & B & Yes & Adequate & Yes & Considerable & 5 \\
\hline & & 3.8 & $\mathrm{C}$ & Yes & $\begin{array}{c}\text { Not } \\
\text { Adequate }\end{array}$ & Yes & $\begin{array}{l}\text { Max Tolerable } \\
\text { for performance }\end{array}$ & 7 \\
\hline \multirow{3}{*}{42} & \multirow{3}{*}{ Light } & 3.10 & $\mathrm{~A}$ & Yes & Desired & Yes & Moderate & 4 \\
\hline & & 3.10 & B & Yes & Desired & Yes & Moderate & 4 \\
\hline & & 3.10 & $\mathrm{C}$ & Yes & $\begin{array}{c}\text { Not } \\
\text { Adequate }\end{array}$ & Yes & $\begin{array}{l}\text { Max Tolerable } \\
\text { for Performance }\end{array}$ & 7 \\
\hline \multirow{3}{*}{43} & \multirow{3}{*}{ Moderate } & 3.11 & A & Yes & Desired & Yes & Moderate & 4 \\
\hline & & 3.11 & B & Yes & Adequate & Yes & $\begin{array}{l}\text { Max Tolerable } \\
\text { for Performance }\end{array}$ & 7 \\
\hline & & 3.11 & $\mathrm{C}$ & In Question & $\begin{array}{c}\text { Not } \\
\text { Adequate }\end{array}$ & Yes & Intense & 9 \\
\hline \multirow[t]{2}{*}{44} & \multirow[t]{2}{*}{$\begin{array}{l}\text { Moderate } \\
\text { or } \\
\text { Greater }\end{array}$} & $\begin{array}{l}1.0 \\
1.0\end{array}$ & $\begin{array}{l}\text { A } \\
\text { A }\end{array}$ & $\begin{array}{l}\text { Yes } \\
\text { Yes }\end{array}$ & $\begin{array}{c}\text { Desired } \\
\text { Not } \\
\text { Adequate }\end{array}$ & $\begin{array}{l}\text { Yes } \\
\text { Yes }\end{array}$ & $\begin{array}{l}\text { Moderate } \\
\text { Moderate }\end{array}$ & $\begin{array}{l}4 \\
5\end{array}$ \\
\hline & & $\begin{array}{l}1.0 \\
1.0 \\
1.0\end{array}$ & $\begin{array}{l}\text { B } \\
\text { B } \\
\text { B }\end{array}$ & $\begin{array}{l}\text { No } \\
\text { No } \\
\text { No }\end{array}$ & $\begin{array}{l}- \\
-\end{array}$ & $\begin{array}{l}- \\
- \\
-\end{array}$ & $\begin{array}{l}- \\
- \\
-\end{array}$ & $\begin{array}{l}10 \\
10 \\
10\end{array}$ \\
\hline \multirow{6}{*}{45} & \multirow{6}{*}{$\begin{array}{l}\text { Very } \\
\text { Smooth }\end{array}$} & 3.3 & $\mathrm{~A}$ & Yes & Desired & Yes & Moderate & 4 \\
\hline & & 3.3 & B & Yes & Adequate & Yes & $\begin{array}{l}\text { Extensive for } \\
\text { Performance }\end{array}$ & 6 \\
\hline & & 3.3 & $\mathrm{C}$ & In Question & $\begin{array}{c}\text { Not } \\
\text { Adequate }\end{array}$ & Yes & $\begin{array}{l}\text { Intense for } \\
\text { control }\end{array}$ & 9 \\
\hline & & 3.4 & A & Yes & Adequate & Yes & Moderate & 4 \\
\hline & & 3.4 & B & Yes & $\begin{array}{c}\text { Not } \\
\text { Adequate }\end{array}$ & Yes & $\begin{array}{l}\text { Max Tolerable } \\
\text { for Performance }\end{array}$ & 7 \\
\hline & & 3.4 & $\mathrm{C}$ & In Question & $\begin{array}{c}\text { Not } \\
\text { Adequate }\end{array}$ & No & $\begin{array}{c}\text { Intense for } \\
\text { Control }\end{array}$ & 9 \\
\hline \multirow{3}{*}{48} & \multirow{3}{*}{$\begin{array}{l}\text { Light to } \\
\text { Moderate }\end{array}$} & 3.5 & A & Yes & Desired & Yes & Considerable & 5 \\
\hline & & 3.5 & B & Yes & $\begin{array}{c}\text { Not } \\
\text { Adequate }\end{array}$ & Yes & Max Tolerable & 7 \\
\hline & & 3.5 & $\mathrm{C}$ & KIO Loads & - & 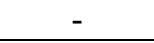 & 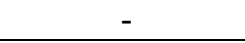 & 10 \\
\hline
\end{tabular}

12

American Institute of Aeronautics and Astronautics 
Table 6a. Expanded Pilot Comments and Notes

\begin{tabular}{|c|c|c|}
\hline FCL & Scenario & Comments and Notes \\
\hline 3.9 & A & Repeated due to cross-wind correction error. \\
\hline 3.9 & B & $\begin{array}{l}\text { Limit cycle roll oscillation all the way to the box. Diverged when I got in loop ... had to stay } \\
\text { out. Once out of loop ... was able to steer to box. }\end{array}$ \\
\hline 3.9 & $\mathrm{C}$ & KIO --- roll. Not controllable. \\
\hline 3.8 & A & had a little bit of limit cycle oscillation. \\
\hline 3.8 & $\mathrm{~B}$ & $\begin{array}{l}\text { I couldn't overcome that large limit cycle oscillation ... couldn't get the airplane going } \\
\text { where I wanted it to go. }\end{array}$ \\
\hline 3.8 & $\mathrm{C}$ & $\begin{array}{l}\text { As soon as the fault was injected it started to roll off and it was accelerating, so I knocked it } \\
\text { off. Peak roll rate } \sim 120 \mathrm{deg} / \mathrm{sec} \text {. }\end{array}$ \\
\hline 3.7 & A & Light turbulence \\
\hline 3.7 & B & $\begin{array}{l}\text { Had limit cycle oscillations that degraded the maneuver. I don't think I was overly } \\
\text { aggressive, had low damping, airplane responded more than I wanted it to. }\end{array}$ \\
\hline 3.7 & $\mathrm{C}$ & $\begin{array}{l}\text {...controllability not in question. I felt like it was controllable, but not controllable enough to } \\
\text { get it in the box. Limit cycle oscillation with neutral stability fault on order of } 30 \mathrm{deg} \text {, this } \\
\text { fault, they were about } 50 \mathrm{deg} \text {....large limit cycle oscillations. I was consciously trying to } \\
\text { not be too aggressive. }\end{array}$ \\
\hline 3.10 & A & $\begin{array}{l}\text { It seemed like it wanted to balloon on me and dive a little bit. It was not quite as predictable } \\
\text { in pitch as I would have liked. Minor but annoying deficiencies. }\end{array}$ \\
\hline 3.10 & B & $\begin{array}{l}\text { Flying it to the box seemed very similar to the no fault case except for some slight limit } \\
\text { cycle roll oscillations superimposed on it. But it really didn't affect my ability to point the } \\
\text { airplane and put it in the box. I was able to move the velocity vector around and put it where } \\
\text { I wanted ... it just had slight roll oscillations. It had the same slightly undesirable pitch } \\
\text { characteristics as the previous scenario. }\end{array}$ \\
\hline 3.10 & $\mathrm{C}$ & $\begin{array}{l}\text { That was a little bit of a wild ride. It seemed that the control law was rapidly changing in its } \\
\text { response characteristics. I don't know if that is that adaptation working. But, it seemed like } \\
\text { I'd be getting a limit cycle [roll] oscillation and that the oscillations would build and then } \\
\text { suddenly it would damp and then the oscillations would build and suddenly damp. }\end{array}$ \\
\hline 3.11 & A & $\begin{array}{l}\text { I was working pretty hard ... making some pretty rapid small inputs that I think were due to } \\
\text { turbulence. }\end{array}$ \\
\hline 3.11 & B & $\begin{array}{l}\text { Performance may not have been adequate [bank angle at touchdown]. We got in the box, but } \\
\text { frankly we were lucky that we got in the box. Adequate performance not attainable with max } \\
\text { tolerable pilot compensation. }\end{array}$ \\
\hline 3.11 & $\mathrm{C}$ & $\begin{array}{l}\text { Barely controllable. I wasn't high gain in the loop, I was just letting it oscillate and just } \\
\text { steering the velocity vector around. It was more that it was oscillating around what I was } \\
\text { trying to command. Compensation was considerable or intense and if you'd have gotten in } \\
\text { the loop with it you may have lost control. This one was so oscillatory that I don't think } \\
\text { turbulence was a factor. }\end{array}$ \\
\hline 1.0 & A & $\begin{array}{l}\text { I think turbulence as a significant factor there. I think without turbulence it would have been } \\
\text { a } 4 \text {, maybe a } 3 \text {. But with the turbulence it was a } 4 \ldots \text { border line } 5 \text {. } \\
\text { When repeated: I'd have to call that a CHR } 5 \text { (not adequate performance). Without } \\
\text { turbulence, I'm assuming I'd have gotten adequate performance. }\end{array}$ \\
\hline 1.0 & B & $\begin{array}{l}\text { I lost control. Diverging roll oscillation. The turbulence was pretty bad on this flight. I think } \\
\text { we were one CHR off [high] because of the turbulence for the "no fault" scenario. With the } \\
\text { fault on turbulence didn't make a difference. }\end{array}$ \\
\hline 1.0 & $\mathrm{C}$ & Not applicable \\
\hline 3.3 & $\bar{A}$ & $\begin{array}{l}\text { We had quite a bit of crosswind on these runs which was a complicating factor. I think that it } \\
\text { was a solid CHR } 4 \text {. Some of my compensation was due to the crosswind. I think if we didn't } \\
\text { have the crosswind it would have been a } 3 \text {. }\end{array}$ \\
\hline
\end{tabular}


Table 6b. Expanded Pilot Comments and Notes (continued)

\begin{tabular}{|c|c|c|}
\hline FCL & Scenario & Comments and Notes \\
\hline 3.3 & B & $\begin{array}{l}\text { It was adequate performance. With the oscillations going on, I didn't feel like I could get in } \\
\text { the loop a whole lot without driving it unstable. It was considerable to extensive } \\
\text { compensation for performance. CHR } 6\end{array}$ \\
\hline 3.3 & $\mathrm{C}$ & $\begin{array}{l}\text { Intense pilot compensation was required for control. We were right on the verge of being out } \\
\text { of control due to roll oscillations. }\end{array}$ \\
\hline 3.4 & A & $\begin{array}{l}\text { On that one I think I botched the lineup due to the crosswind. I think without the crosswind it } \\
\text { would have been desired performance. It was moderate compensation. CHR } 4 \text {. }\end{array}$ \\
\hline 3.4 & B & $\begin{array}{l}\text { I think I was mostly able to steer the velocity vector of the airplane, but superimposed on } \\
\text { that, I had large amplitude roll oscillations. So, we were not adequate performance and had } \\
\text { max tolerable compensation. CHR } 7 \text {. }\end{array}$ \\
\hline 3.4 & $\mathrm{C}$ & Pretty wild. Barely controllable. We were right on the edge of losing control. CHR 9 \\
\hline 3.5 & A & $\begin{array}{l}\text { Just inside desired. I'd say it required considerable pilot compensation. I don't know if } \\
\text { turbulence or crosswind was a factor. I was working pretty hard; I'd call that moderately } \\
\text { objectionable deficiency. Excessive throttle activity made it hard to know when it was } \\
\text { trimmed. The throttle was always moving and that couples into pitch, so it was hard to know } \\
\text { when I was trimmed. }\end{array}$ \\
\hline 3.5 & B & $\begin{array}{l}\text { Deficiencies were not tolerable. Max tolerable compensation ... major deficiencies. CHR } 7 \text {. } \\
\text { It was primarily the roll axis, but the pitch axis was difficult as well. }\end{array}$ \\
\hline 3.5 & $\mathrm{C}$ & KIO - loads. Task abandoned due to normal load factor. $(+2.3 \mathrm{~g}$ to $-0.25 \mathrm{~g})$. \\
\hline
\end{tabular}

Table 7. Summary Cooper-Harper Ratings

\begin{tabular}{|c|l|c|c|c|}
\hline \multicolumn{2}{|c|}{ Flight Control Law } & \multicolumn{3}{c|}{ Cooper-Harper Rating } \\
\cline { 3 - 5 } & No Failure & \multicolumn{2}{c|}{ Failure Simulation } \\
\hline ID & \multicolumn{1}{|c|}{ Design Method } & Baseline & Neutral Stability & Unstable \\
\hline 3.10 & $\begin{array}{l}\text { Composite MRAC } \\
\text { Adaptive Augmentation }\end{array}$ & $\mathbf{4}$ & $\mathbf{4}$ & 7 \\
\hline 3.7 & $\begin{array}{l}\text { L1 } \\
\text { All Adaptive }\end{array}$ & $\mathbf{3}$ & $\mathbf{5}$ & 7 \\
\hline 3.3 & $\begin{array}{l}\text { Deriv. Free MARC } \\
\text { Adaptive Augmentation }\end{array}$ & $\mathbf{4}$ & $\mathbf{6}$ & $\mathbf{9}$ \\
\hline 3.9 & $\begin{array}{l}\text { H-Infinity } \\
\text { Robust Linear }\end{array}$ & $\mathbf{3}$ & $\mathbf{5}$ & $\mathbf{1 0}$ \\
\hline 3.5 & $\begin{array}{l}\text { LQR } \\
\text { Integrated Propulsion }\end{array}$ & $\mathbf{5}$ & 7 & $\mathbf{1 0}$ \\
\hline 3.11 & $\begin{array}{l}\text { LQR-PI } \\
\text { Linear Optimal }\end{array}$ & $\mathbf{4}$ & 7 & $\mathbf{9}$ \\
\hline 3.4 & $\begin{array}{l}\text { LQR } \\
\text { Linear Optimal }\end{array}$ & $\mathbf{4}$ & 7 & $\mathbf{1 0}$ \\
\hline 3.8 & $\begin{array}{l}\text { Stability Augmentation } \\
\text { Classical Linear }\end{array}$ & $\mathbf{3}$ & $\mathbf{8}$ & $\begin{array}{c}\text { Not } \\
\text { Attempted }\end{array}$ \\
\hline Direct & $\begin{array}{l}\text { Stick to Surface } \\
\text { Open-Loop }\end{array}$ & $\mathbf{4}$ & $\mathbf{1 0}$ & \\
\hline
\end{tabular}

14

American Institute of Aeronautics and Astronautics 


\section{Concluding Remarks}

One of the objectives of the NASA Aviation Safety Program's IRAC project was to advance the state of the art of adaptive flight control technologies as a design option to provide enhanced stability and maneuverability margins for safe landing in the presence of adverse conditions, including damage and failures. One of the benefits of that objective is improved survivability following failures or damage. A single pilot provided Cooper-Harper Ratings to evaluate the controllability using a suite of adaptive and non-adaptive flight control laws to perform an offset-tolanding task. A remotely piloted 5.5\% dynamically scaled generic transport model airplane was used for the task. A buildup approach was used to conduct this task evaluation for a set of complex multi-axis failure scenarios. The scenarios used redundant control surfaces and an in-flight simulation approach to simultaneously: decrease control surface effectiveness, decrease longitudinal static stability, and decrease roll damping.

For the control laws evaluated in this screening study, the adaptive control laws provided the best combination of handling qualities retention and controllability over the full range of failure scenarios tested. The robustness indicated by high time-delay margins displayed by the linear controllers did not imply an ability to handle the degraded stability failure case. For these failure cases, the controllers with good ability to track pilot commands (as opposed to controllers with high time delay margin) received superior pilot ratings. A robust linear controller with reference command inputs provided handling qualities retention comparable to the adaptive control laws for the neutral stability failure. However, when using that controller, the handling qualities abruptly degraded for the more severe failure. All of the control laws tested (adaptive and non-adaptive) provided significantly better handling qualities than did the direct control mode when the stability and control degradation scenarios were introduced. 

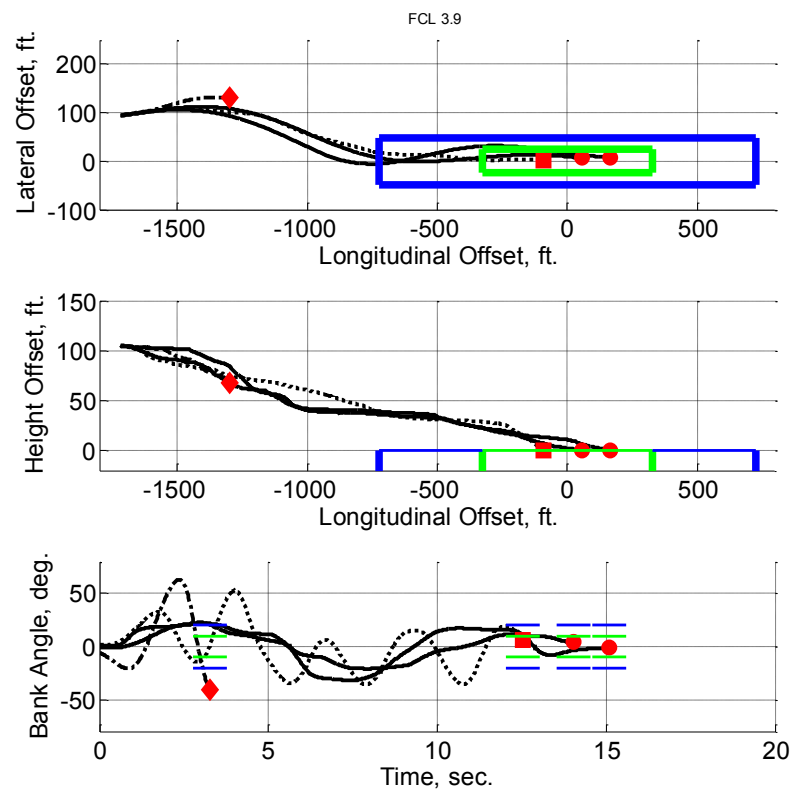

Figure 8. Time history and offset landing trajectories for FCL \#3.9. Circles denote scenario " $A$ " - no failure, squares denote scenario " $B$ " - neutral stability, diamonds denote scenario " $C$ " unstable; Green boundary denotes desired range, blue boundary denotes adequate range.
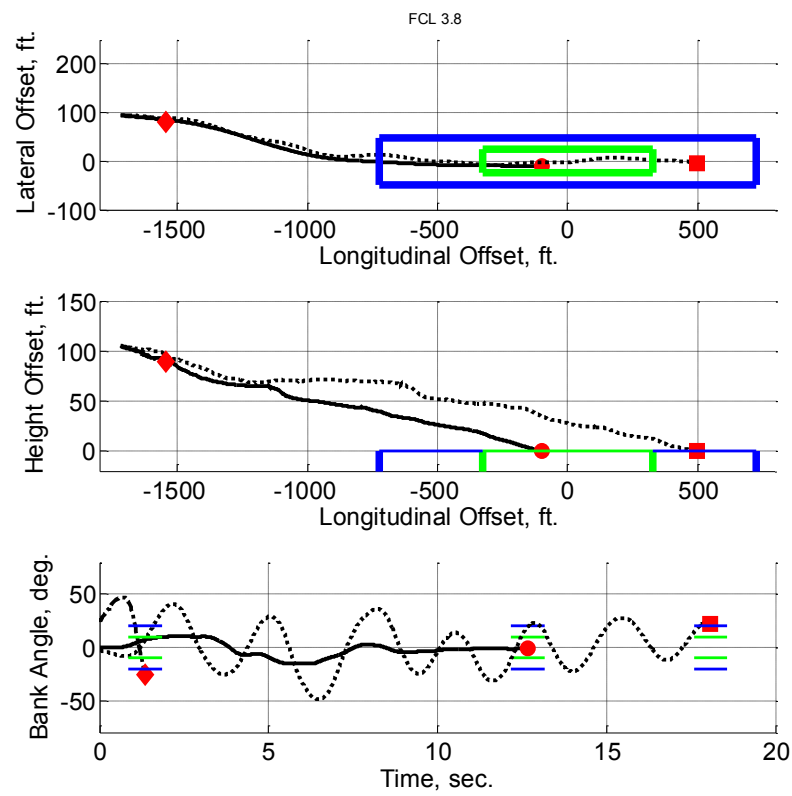

Figure 9. Time history and offset landing trajectories for FCL \#3.8. Circles denote scenario " $A$ " - no failure, squares denote scenario " $B$ " - neutral stability, diamonds denote scenario " $C$ " unstable; Green boundary denotes desired range, blue boundary denotes adequate range. 

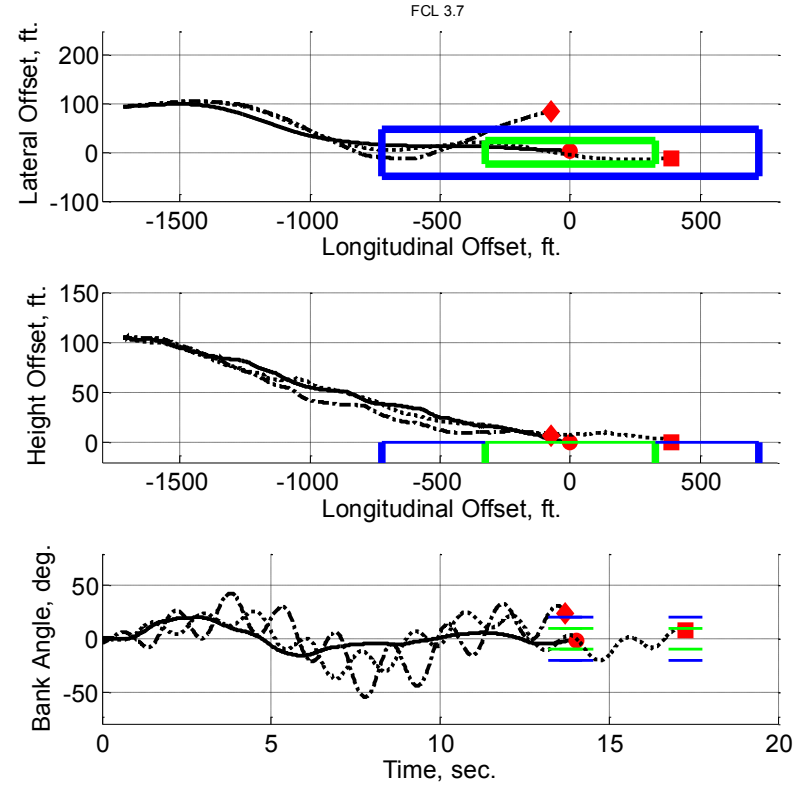

Figure 10. Time history and offset landing trajectories for FCL \#3.7. Circles denote scenario " $A$ " - no failure, squares denote scenario " $B$ " - neutral stability, diamonds denote scenario " $C$ " unstable; Green boundary denotes desired range, blue boundary denotes adequate range.
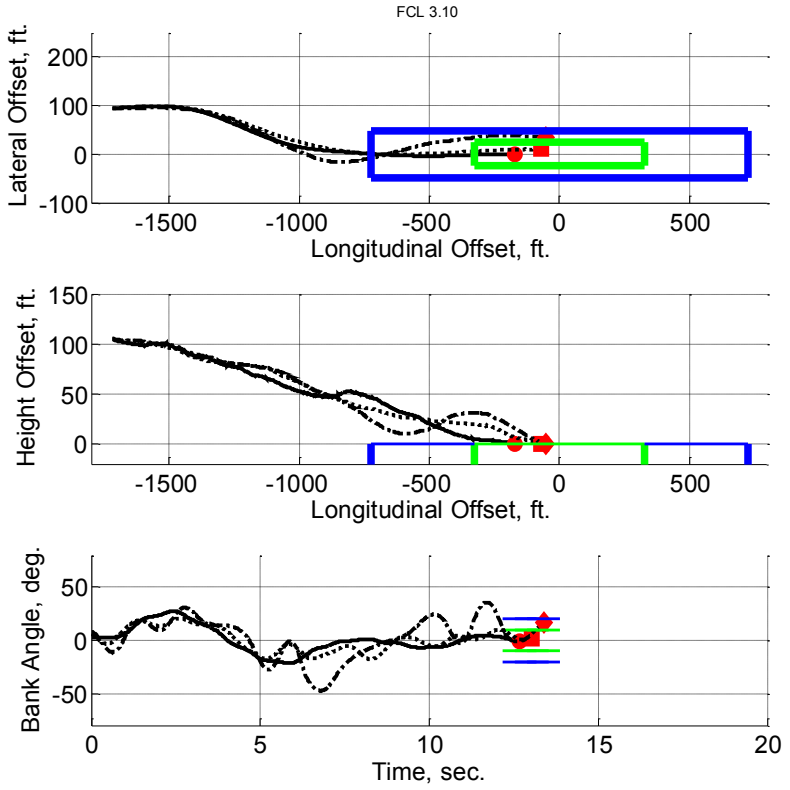

Figure 11. Time history and offset landing trajectories for FCL \#3.10. Circles denote scenario " $A$ " - no failure, squares denote scenario " $B$ " - neutral stability, diamonds denote scenario " $C$ " unstable; Green boundary denotes desired range, blue boundary denotes adequate range. 

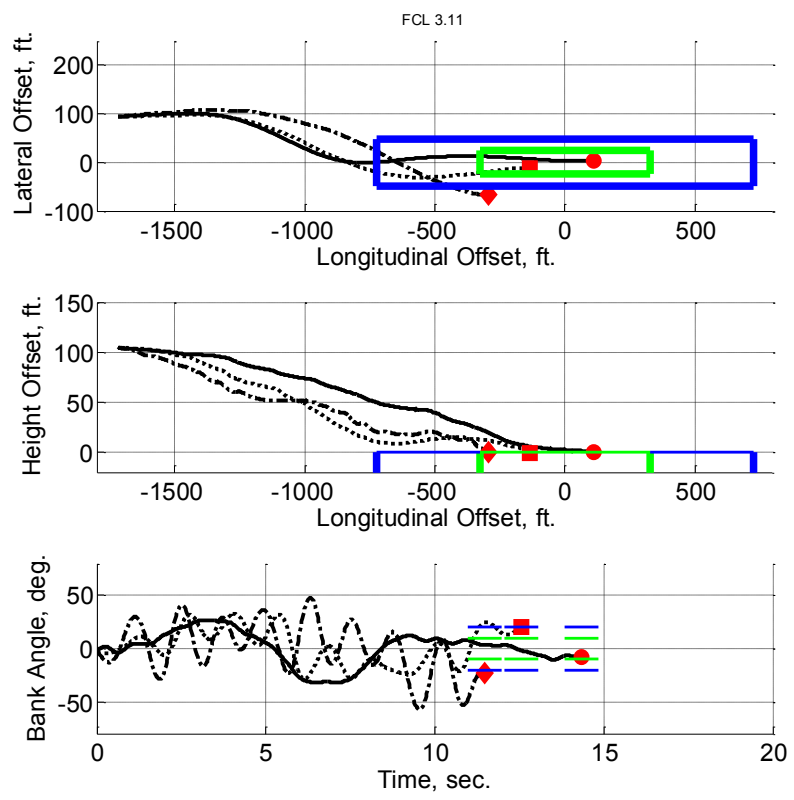

Figure 12. Time history and offset landing trajectories for FCL \#3.11. Circles denote scenario " $A$ " - no failure, squares denote scenario " $B$ " - neutral stability, diamonds denote scenario " $C$ " unstable; Green boundary denotes desired range, blue boundary denotes adequate range.
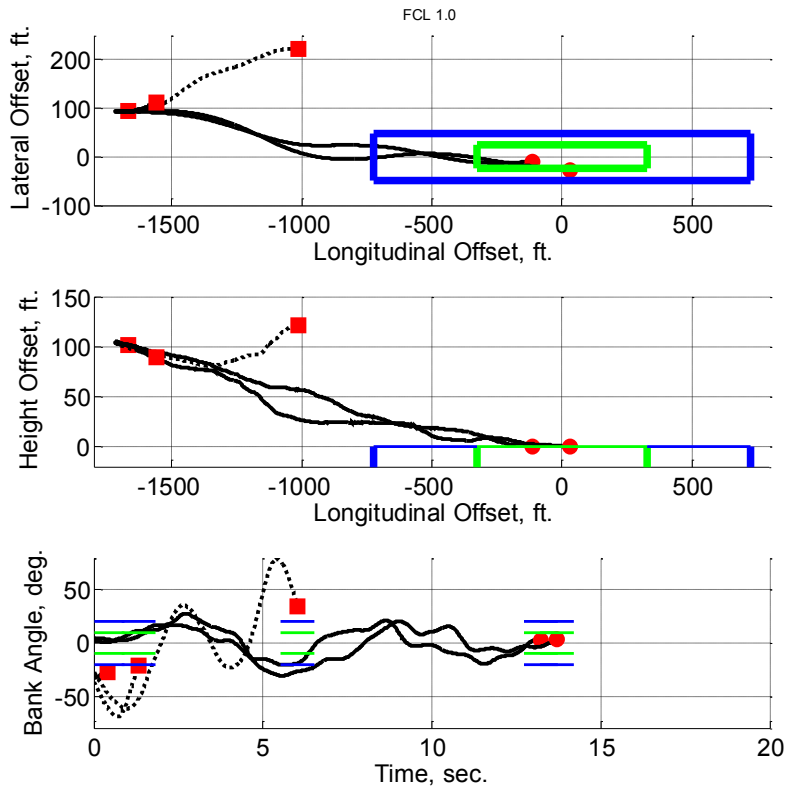

Figure 13. Time history and offset landing trajectories for FCL \# 1.0. Circles denote scenario " $A$ " - no failure, squares denote scenario " $B$ " - neutral stability, diamonds denote scenario " $C$ " unstable; Green boundary denotes desired range, blue boundary denotes adequate range.

American Institute of Aeronautics and Astronautics 

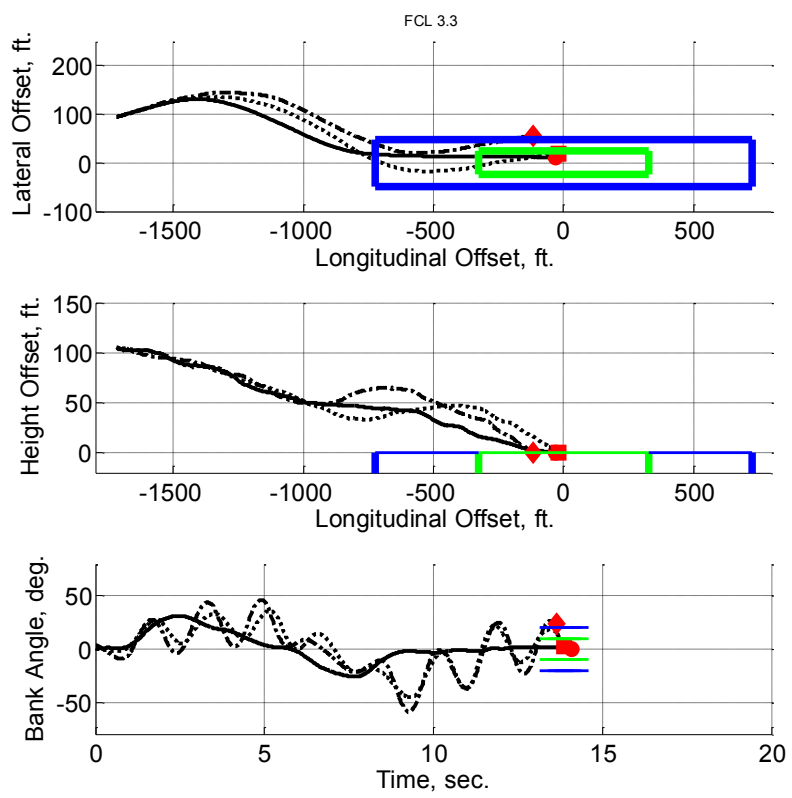

Figure 14. Time history and offset landing trajectories for FCL \#3.3. Circles denote scenario " $A$ " - no failure, squares denote scenario " $B$ " - neutral stability, diamonds denote scenario " $C$ " unstable; Green boundary denotes desired range, blue boundary denotes adequate range.
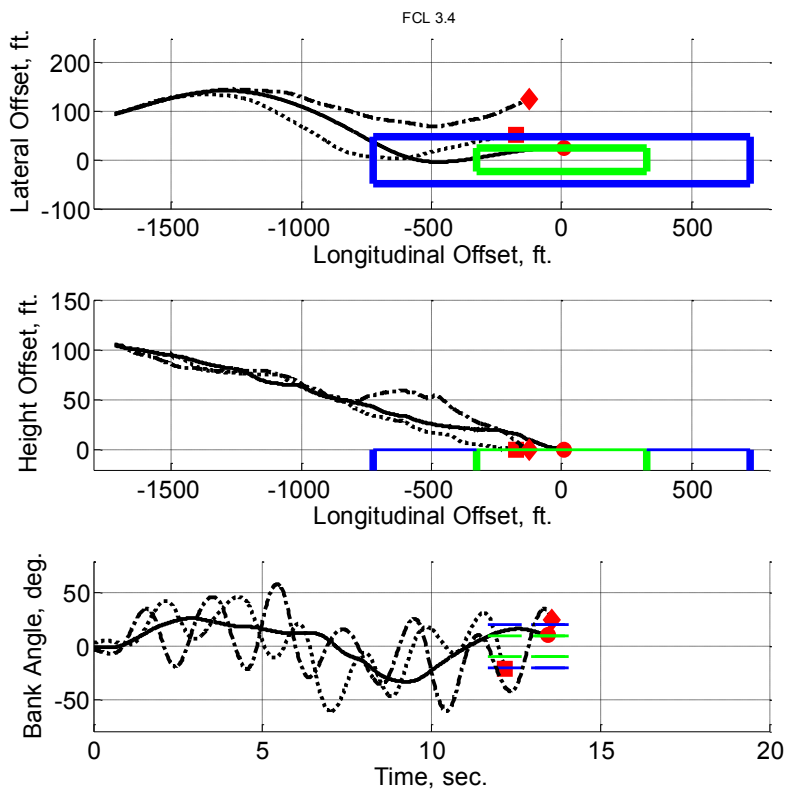

Figure 15. Time history and offset landing trajectories for FCL \#3.4. Circles denote scenario " $A$ " - no failure, squares denote scenario " $B$ " - neutral stability, diamonds denote scenario " $C$ " unstable; Green boundary denotes desired range, blue boundary denotes adequate range. 

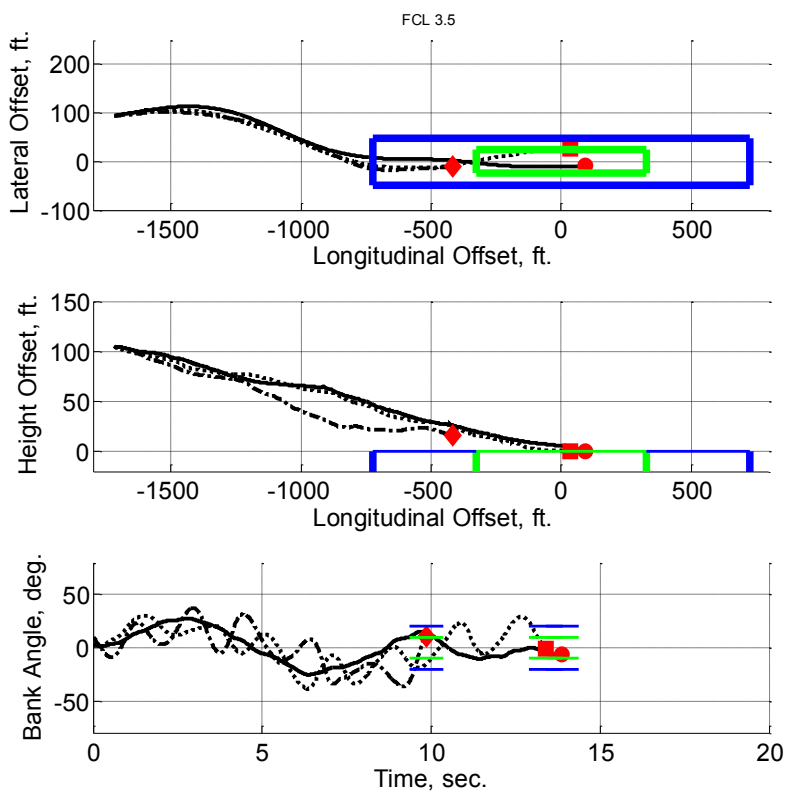

Figure 16. Time history and offset landing trajectories for FCL \#3.5. Circles denote scenario " $A$ " - no failure, squares denote scenario " $B$ " - neutral stability, diamonds denote scenario " $C$ " unstable; Green boundary denotes desired range, blue boundary denotes adequate range.

\section{References}

${ }^{1}$ Belcastro, Christine M. and Foster, John V., "Aircraft Loss-of-Control Accident Analysis”, AIAA Guidance, Navigation, and Control Conference, Toronto, Canada, 2010.

${ }^{2}$ Shah, Gautam H., Cunningham, Kevin, Foster, John V., Fremaux, C. Michael, Stewart, Eric C., Wilborn, James E., Gato, William, Pratt, Derek W.; "Wind-Tunnel Investigation of Commercial Transport Aircraft Aerodynamics at Extreme Flight Conditions", SAE 2002-01-2912, World Aviation Congress \& Display, November 5-7, 2002.

${ }^{3}$ Foster, John V, et al, "Dynamics Modeling and Simulation of Large Transport Airplanes in Upset Conditions", AIAA2005-5933, AIAA Atmospheric Flight Mechanics Conference, AIAA, San Francisco, CA, 2005.

${ }^{4}$ Murch, Austin M. and Foster, John V.; "Recent NASA Research on Aerodynamic Modeling of Post-Stall and Spin Dynamics of Large Transport Airplanes", AIAA-2007-463-253, 45 ${ }^{\text {th }}$ AIAA Aerospace Sciences Meeting and Exhibit, 8-11 January 2007, Reno, Nevada.

${ }^{5}$ Jordan, Thomas L., Foster, John V., Bailey, Roger M., and Belcastro, Christine M.; "AirSTAR: A UAV Platform for Flight Dynamics and Control System Testing", AIAA-2006-3307.

${ }^{6}$ Murch, A. M., "A Flight Control System Architecture for the NASA AirSTAR Flight Test Facility," AIAA 2008-6990, AIAA Guidance, Navigation, and Control Conference and Exhibit, Honolulu, HI, 2008.

${ }^{7}$ Wolowicz, C. H.; Bowman, J. S.; and Gilbert, W. P., "Similitude Requirements and Scaling Relationship as Applied to Model Testing", NASA Technical Paper 1435, August, 1979.

${ }^{8}$ Yucelen, T. and Calise, A. J., "Derivative-Free Model Reference Adaptive Control”, AIAA-2010-7769, AIAA Guidance, Navigation, and Control Conference, 2-5 August 2010, Toronto, Canada.

${ }^{9}$ Crespo, L. G., Metsutani, M., and Annaswamy, A. M., "Design of a Model Reference Adaptive Controller for an Unmanned Air Vehicle", AIAA-2010-8049, AIAA Guidance, Navigation, and Control Conference, 2-5 August 2010, Toronto, Canada.

${ }^{10}$ Gregory, I. M., Cao, C., Xargay, E., and Zou X., "L1 Adaptive Control Design for NASA AirSTAR Flight Test Vehicle", AIAA 2009-5738, AIAA Guidance, Navigation, and Control Conference, 10-13 August 2009, Chicago, Illinois.

${ }^{11}$ Dorobantu, A., Murch, A. M., and Balas, G. J., "H-Infinity Robust Control Design for the NASA AirSTAR Flight Test Vehicle", Submitted to the $50^{\text {th }}$ AIAA Aerosciences Meeting, Jan. 2012, Nashville, Tennessee.

${ }^{12}$ Gadient, R., Levin, J., and Lavretsky, E., "Comparison of Model Reference Adaptive Controller Designs Applied to the NASA Generic Transport Model”, AIAA 2010-8406, AIAA Guidance, Navigation and Control Conference, 2-5 August 2010, Toronto, Canada. 